\title{
Machining of Composite Materials by Ultrasonic Assistance
}

\author{
Marcel Kuruc ${ }^{1}$ \\ 1 Slovak University of Technology in Bratislava, Faculty of Materials Science and Technology in Trnava, Institute \\ of Production Technologies, Jána Bottu 23, 91724 Trnava, Slovakia \\ e-mail: marcel.kuruc@stuba.sk
}

\begin{abstract}
A lot of studies are focused on decreasing the weight of the manufactured components and increasing their mechanical properties or achieving additional unique properties. One of the results of their effort is a composite material. This kind of material consists of two phases - matrix and reinforcing phase. This unique combination of phases causes the superior properties of the composite material. However, since the material properties of the matrix differ from the material properties of the reinforcing material, certain difficulties during machining are caused. These difficulties include: delamination of the machined composite and reduced tool life. Those facts motivate other studies to investigate the machinability of the composite materials. A few possibilities on how to improve the machining process during the machining of composite materials were described. For example, Seco Tools Company started with developing a new shape of the cutting tools; DMG Mori Company successfully implemented the assistance of the ultrasound into the milling process and therefore achieved the enhanced machinability od the materials; the scientists from the Stan-ford University developed a diamond-like carbon (DLC) coating, which is available to satisfactory cut the reinforcing fibres as well as the soft matrix. This article compared the ultrasonicassisted face milling of the carbon fibre reinforced plastic (CFRP) and glass fibre reinforced plastic (GFRP) by a unique shaped milling cutter. Delamination of those composite materials during the milling process was observed via $3 \mathrm{D}$ digitization devices. The results of the research could be applied to determine how a fibre material can affect the ultrasonic assistance during the milling process. Lower delamination during machining of GFRP was achieved; however, lower surface roughness was obtained during the machining of CFRP.
\end{abstract}

Keywords: Ultrasonic assisted milling, CFRP, GFRP, Delamination.

\section{INTRODUCTION}

Composite materials consist of two different phases. The reinforcing phase, which can be in the form of fibres, is usually hard and strong. In turn, the matrix phase is usually soft and tough, and its purpose is to keep reinforcing the phase together. Different mechanical properties of each phase are causing difficulties during its machining. The machining parameters recommended for reinforcing the fibre differ from the machining parameters recommended for the matrix. Therefore, the machining parameters which are correct for one phase of composite material are incorrect for other phases. Incorrect machining parameters could cause problems during machining, such as tearing out the fibres, melting of the matrix, rapid tool wear, edge-chipping of the machined material, etc. Different approaches to solve the abovementioned difficulties were presented. One of them is a modification of the design of the cutting tool. Modern cutting tools dedicated to the machining of the composite materials usually have a unique shape and geometry. They could have a double screw shaped like an arrow, or pineapple-like shape, or additional notches on the cutting edges. Another approach deals with advanced coatings, such as diamond coating, or DLC (diamond-like carbon) coating, CBN coating, etc. Yet another option of improving the machining process of the materials is the assistance of ultrasound. Ultrasound dramatically reduces the creation of BUE, decreases the cutting forces and lowers the process heat. The cutting parameters are still affected by the type of the reinforcing material and the type of matrix. Moreover, 
different machining parameters are adjusted for the roughing and finishing process [1-9].

\section{DESCRIPTION AND RESULTS OF THE EXPERIMENT}

In the experiment, a DMG Ultrasonic 20 linear machine tool was applied for ultrasonic-assisted machining. In the cutting process, the tool oscillates by ultrasonic frequency in the vertical direction and rotates around the vertical axis. The nenefits of the ultrasonic-assisted process include the reduction of the process heat generation, a decrease of the cutting forces, lack of chemical influence on the workpiece, a decrease of the tool wear, superior machined surface, etc. [10, 11, 12]. A face milling tool for the machining of composite materials was used as a cutting tool. This tool has the cutting length (maximum depth of cut) of $18 \mathrm{~mm}$, shank diameter of $6 \mathrm{~mm}$, the cutting diameter of $5 \mathrm{~mm}$ (reduction of diameter works as concentrator of ultrasonic energy), overall length of $60 \mathrm{~mm}$ and 8 flutes (teeth) $[13,14]$. The used machine tool and the mentioned milling cutter are shown in Figure 1.

A carbon fibre reinforced plastic (CFRP) and a glass fibre reinforced plastic (GFRP) were used as the workpiece materials. The machining parameters used in the experiments are presented in Table 1.

Several grooves were made into CFRP and GFRP workpiece materials. The grooves were $0.7 \mathrm{~mm}$ deep. After the machining process, the resultant workpiece materials were digitised by GOM ATOS II TripleScan optical scanner and by Zeiss Metrotom 1500 computer tomography. The obtained digitised models were compared with the reference CAD model. The delamination factor was evaluated according to the highest width of each groove (reference width was equal to the cutting diameter of the cutting tool $-5 \mathrm{~mm}$ ). Besides the delamination factor, the surface roughness was also evaluated (rough surface is often accompanied by delamination). The surface roughness was measured by the device for measuring the profile and surface roughness - Zeiss Surfcom 5000. All the abovementioned devices for measuring and evaluation of delamination are shown in Figure $2[16,17]$.

The delamination of CFRP and GFRP composite material were evaluated by the following parameters: delamination factor (resultant width of the grooves); and selected surface roughness parameters. Those parameters were obtained for each machined groove. The results were influenced by the orientation of the grooves due to the direction of the reinforcing fibres. The labelling of the grooves is shown in Figure 3. The direction of the fibres is vertical - parallel with grooves 1 and 3 on CFRP and with groove 2 in GFRP.

Each measurement of the delamination factor, as well as surface roughness, was repeated three times. However, only the average values were recorded in the table. The delamination factor is labelled as $D_{f}$ and it is calculated as the percentage difference between the reference width of the groove and the real width of the groove, which is usually greater than the reference width. The principle is illustrated in Figure 4 and expressed by formula (1). The average $(R a)$ and maximum $(R z)$ values of the roughness were selected as the surface roughness parameters.
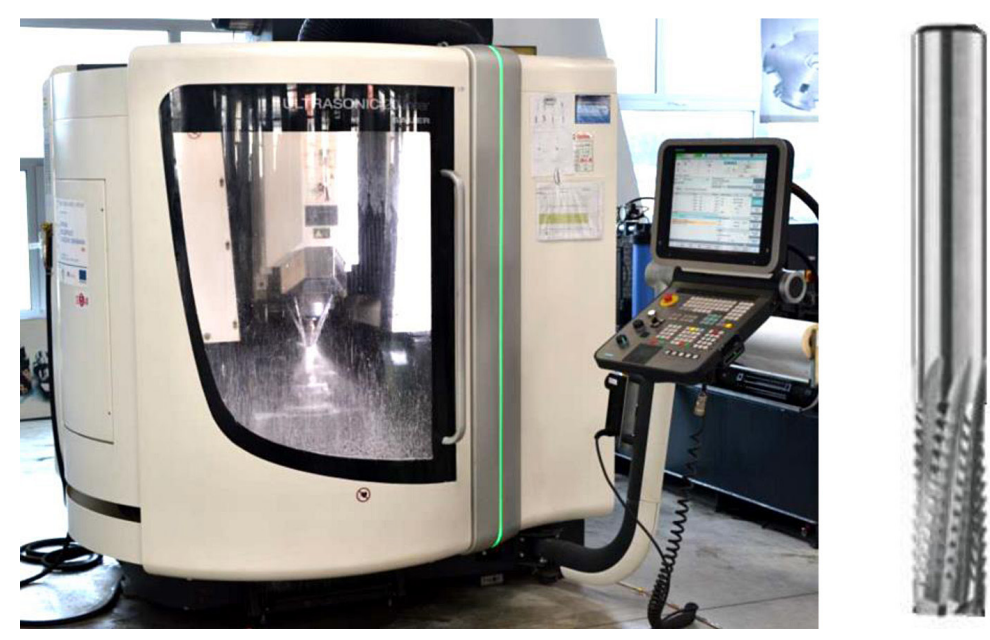

Fig. 1. Rotary ultrasonic machine tool and milling cutter for composite materials 
Table 1. Recommended parameters for machining of composites [15]

\begin{tabular}{|l|c|c|c|}
\hline \multicolumn{1}{|c|}{ Parameter } & Unit & CFRP & GFRP \\
\hline Ultrasonic frequency & $\mathrm{kHz}$ & 23.5 & 23.5 \\
\hline Depth of cut & $\mathrm{mm}$ & 0.7 & 0.7 \\
\hline Cutting speed & $\mathrm{m} / \mathrm{min}$ & 100 & 50 \\
\hline Spindle speed & $\mathrm{rpm}$ & 6366 & 3183 \\
\hline Feed per tooth & $\mathrm{mm}$ & 0.015 & 0.015 \\
\hline Feed rate & $\mathrm{mm} / \mathrm{min}$ & 764 & 382 \\
\hline
\end{tabular}

A pale blue colour represents the reference width of the groove (W) and brown colour represents the actual (maximum) width of the groove $\left(\mathrm{W}_{\max }\right)$. According to Fig. 4 is possible to calculate the delamination factor by the following formula:

$$
D_{f}=\left(\frac{W_{\max }-W}{W}\right) \times 100[\%]
$$

The results of the performed measurements are evaluated in Table 2. Only the average values (each measurement was repeated three times) were recorded. The last average value is the mean value of all four positions of the grooves.

When the delamination was lesser than the accuracy of the digitization device (it was not observed on the digitized model), the value of the delamination factor was labelled as less than $0.2 \%$. Therefore, it cannot be precisely calculated (it looks like there is no delamination).

\section{CONCLUSION}

The obtained and evaluated results of measuring the delamination and comparison of the results between both types of reinforcing fibres of the polymer composites enabled to conclude that the value of delamination is affected by the reinforcing fibre material. A lower delamination factor was observed during the machining of GFRP (lower by $74 \%$ in comparison with CFRP). The worst value of the all was achieved

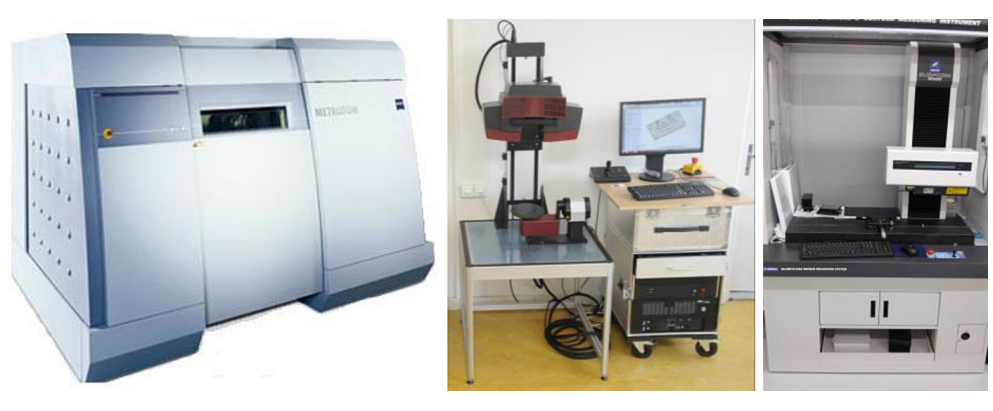

Fig. 2. Measuring devices [16, 17]: a) Zeiss Metrotom 1500,

b) GOM ATOS II TripleScan, c) Zeiss Surfcom 5000
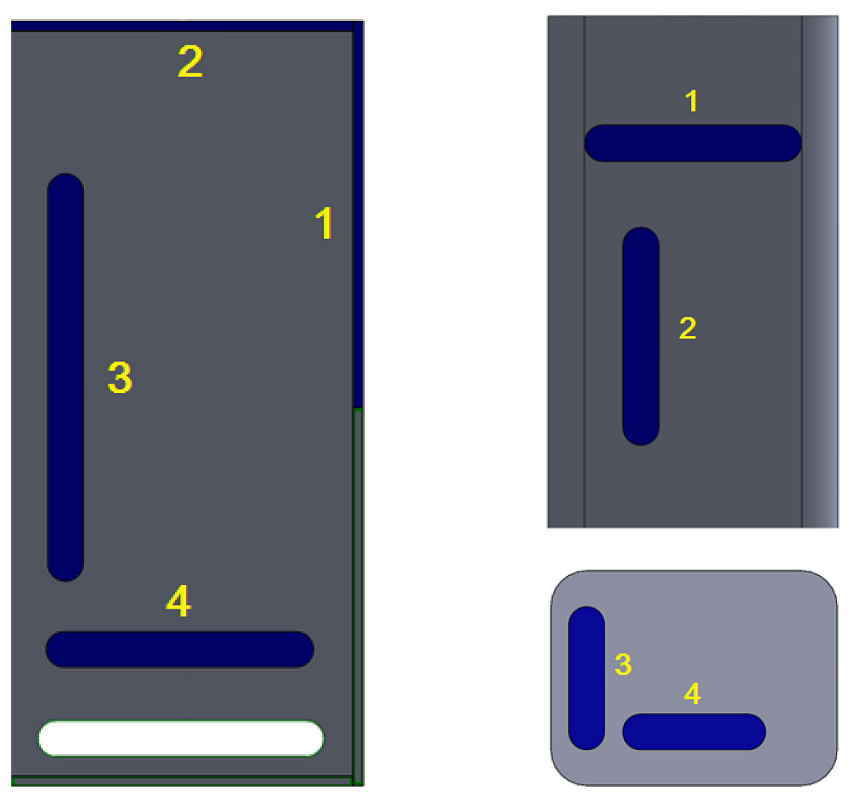

Fig. 3. Labeling of the grooves: a) CFRP, b) GFRP 
Table 2. The results of the measurements of CFRP and GFRP composite material

\begin{tabular}{|c|c|c|c|c|c|c|}
\hline \multirow{2}{*}{ Position } & \multicolumn{5}{|c|}{ CFRP } & \multicolumn{3}{c|}{ GFRP } \\
\cline { 2 - 7 } & $\mathrm{D}_{\mathrm{f}}[\%]$ & $\mathrm{Ra}[\mu \mathrm{m}]$ & $\mathrm{Rz}[\mu \mathrm{m}]$ & $\mathrm{D}_{\mathrm{f}}[\%]$ & $\mathrm{Ra}[\mu \mathrm{m}]$ & $\mathrm{Rz}[\mu \mathrm{m}]$ \\
\hline 1 & 1.9 & 1.15 & 7.34 & 14.8 & 2.86 & 17.25 \\
\hline 2 & 38.1 & 0.92 & 6.92 & 3.6 & 3.18 & 17.35 \\
\hline 3 & 17.0 & 2.15 & 18.60 & $<0.2$ & 1.56 & 10.59 \\
\hline 4 & 14.2 & 1.45 & 9.42 & $<0.2$ & 1.59 & 11.42 \\
\hline Average & 17.8 & 1.42 & 10.57 & $<4.7$ & 2.29 & 14.15 \\
\hline
\end{tabular}

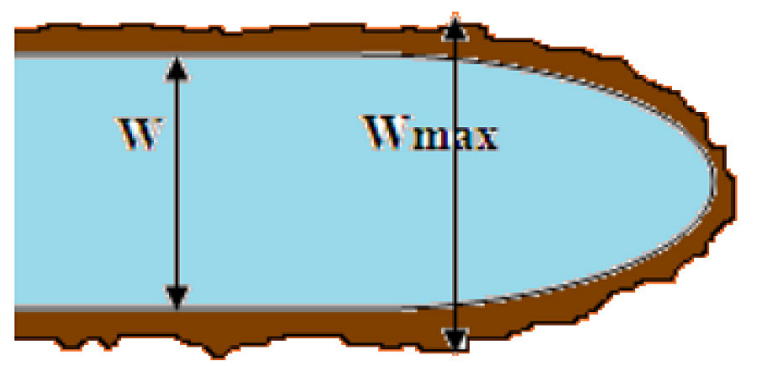

Fig. 4. Delamination of the notch [8]

in CFRP at groove 2, which is perpendicular to the carbon fibres axis direction. The best value of the delamination factor for the CFRP was obtained at the groove 1 , which is parallel to the carbon fibres direction. No delamination was observed at the grooves 3 and 4 after machining of GFRP (both grooves are perpendicular to the glass fibres axis direction); therefore, there the lowest delamination factor was obtained. The worst delamination for GFRP was observed at the groove 1 , which is perpendicular across the glass fibres direction.

The surface roughness parameters did not copy the behaviour of the delamination factor. While the delamination factor was generally lower for GFRP, the surface roughness achieved lower values in the case of milling of CFRP. A reduction of the Ra parameter by $38 \%$ and the Rz parameter by $25 \%$ were observed. The lowest surface roughness parameters of all was achieved in CFRP at groove 2, which is perpendicular to the carbon fibres axis direction. The worst roughness of the all was achieved in GFRP at groove 2, which is parallel to the glass fibres direction.

To sum up, the properties of carbon fibres cause lower surface roughness, but higher delamination factor in comparison with glass fibres. Generally, the better results were achieved at the grooves perpendicular to the fibres axis direction. Relatively low values of delamination were obtained due to the advanced design of the cutting tool (purpose of the milling cutter is the machining of fibre composites). The obtained results could be used for cutting edge preparation. Further research will be focused on the influence of the different cutting-edge preparation and comparison of the delamination of the selected composite materials via the cutting edge prepared by means of a milling cutter with a conventional milling tool.

\section{Acknowledgment}

The article was written with the support of the Project of VEGA grant agency of the Ministry of Education, Science, Research and Sport of the Slovak Republic and Slovak Academy of Sciences, no. 1/0097/17: "The research of novel method for cutting edge preparation to increase the tool performance in machining of difficult-tomachine materials".

\section{REFERENCES}

1. Akbari J., et al.: Applying Ultrasonic Vibration to Decrease Drilling-Induced Delamination in GFRP Laminates. Procedia CIRP, 6, 2013, 577-582.

2. Bosco M.A.J., Palanikumar K., Prasad B.D., Velayudham A.: Influence of Machining Parameters on Delamination in Drilling of GFRP-armour Steel Sandwich Composites. Procedia Engineering, 51, 2013, 758-763.

3. Khan M.A., Kumar A.S.: Machinability of glass fibre reinforced plastic (GFRP) composite using alumina-based ceramic cutting tools. Journal of Manufacturing Process, 13(1), 2011, 67-73.

4. Ning F., Wang H., Cong W., Fernando P.K.S.C.: A mechanistic ultrasonic vibration amplitude model during rotary ultrasonic machining of CFRP. Ultrasonics, 76, 2017, 44-51.

5. Palanikumar K.: Experimental investigation and optimisation in drilling of GFRP composites. Measurement, 44(10), 2011, 2138-2148.

6. Sonkar V., Abhishek K., Datta S., Mahapatra S.S.: Multi-objective Optimization in Drilling of GFRP Composites: A Degree of Similarity Approach. Procedia Materials Science, 6, 2014, 538-543. 
7. Sreenivasaulu R.: Optimization of Surface Roughness and Delamination Damage of GFRP Composite Material in End Milling using Taguchi Design Method and Artificial Neural Network. Procedia Engineering, 64. 2013, 785-794.

8. Stawarz S., Stawarz M., Kucharczyk W., Żurowski W., Różycka A.: New polymer composites including a phenol-formaldehyde resin binder designed for self-lubricating sliding pair elements. Advances in Science and Technology Research Journal. 13(4), 2019, 223-229.

9. Su Z., Jia Z., Niu B., Bi G.: Size effect of depth of cut on chip formation mechanism in machining of CFRP. Composite Structures, 164, 2017, 316-327.

10. Kuruc M., Zvončan M., Peterka J.: Investigation of ultrasonic assisted milling of aluminum alloy AlMg4.5Mn. Procedia Engineering, 69, 2014, 1048-1053.

11. Kuruc M.: Machine tool loads in rotary ultrasonic machining of alumina, $\mathrm{CBN}$ and synthetic diamond. In: Proceedings of the 26th DAAAM International Symposium, 2015, 519-523.
12. Kuruc M., Vopát T., Peterka J.: Surface Roughness of Poly-crystalline Cubic Boron Nitride after Rotary Ultrasonic Machining. Procedia Engineering, 100, 2015, 877-884.

13. Hufschmied: Catalogue Plastic-Machining. Available on the Internet: http://www.hufschmied.net/tl files/dokumente/HUF-Kuststoff-Low-080415.pdf

14. Zvončan M., Kováč M., Beňo M.: Machine tool's DMG Ultrasonic 20 linear simulation in Powermill CAM software. CA Systems in Production Planning. 12(1), 2012, 90-93.

15. SECO Tools. Monolithic Carbide Mills. Available on the Internet: https://www.secotools.com/CorpWeb/Czech\%20Republic

16. Zeiss. SURFCOM 5000. Available on the Internet: http://www.zeiss.com/industrial-metrology/en_de/ products/systems/form-andsurface/surface-andcontour/surfcom-5000.html

17. Zeiss. Metrotom 1500. Available on the Internet: http://www.zeiss.com/industrial-metrology/en de/ products/systems/computedtomography/metrotom-1500.html 